\title{
Red Degeneration of Leiomyoma: An Unusual Presentation
}

\author{
Savita A Somalwar ${ }^{1}$, Nirwana Agrawal ${ }^{2}$, Anjali Kawthalkar ${ }^{3}$, Sadhana Mahore ${ }^{4}$, Nikita Vijay ${ }^{5}$
}

\begin{abstract}
Red degeneration of leiomyoma is a rare type of degeneration. Hyaline, calcareous, and fatty degenerations are being more common. It is a medical enigma because of its peculiar and acute presentation associated with pregnancy. Red degeneration of fibroid is very rare in nonpregnant women. Although uncommon, a gynecologist should be aware of the entity for timely diagnosis and treatment. Here two cases of red degeneration in nonpregnant women are reported. In the first case, a woman was reported with menorrhagia, fever, pain, and urinary complaints. Red degeneration of fibroid was not suspected and, to utter surprise, the histopathology report was suggestive of red degeneration of fibroid. In the second case, a woman was presented with a lump and pain in the abdomen, and history of fever. On the basis of the previous experience, clinical diagnosis of red degeneration was considered. It was confirmed by histopathology.

Keywords: Benign tumor of uterus, Fibroid uterus, Leiomyoma of uterus, Red degeneration of fibroid.

Journal of South Asian Federation of Obstetrics and Gynaecology (2019): 10.5005/jp-journals-10006-1713
\end{abstract}

\section{INTRODUCTION}

Red degeneration of fibroid is common in pregnancy and rarely seen in nonpregnant women. It may occur in women when fibroid is treated with gonadotrophin analogs or managed with uterine artery embolization. ${ }^{1}$ Here two cases of red degeneration in nonpregnant women are reported. In the first case, diagnosis was made after the histopathology report and in the second case diagnosis was made preoperatively, which was confirmed by histopathology.

\section{Case Description}

\section{Case 1}

Mrs. KY, 38 years old, was admitted with history of menorrhagia and incomplete evacuation of the bladder since 2 months, pain in the lower abdomen since 3 days, fever since 2 days, and retention of urine since 24 hours. She was two para with full-term normal deliveries and tubal ligation was done. She had previous eumenorrheic cycles and the last menstrual period was 15 days back. There was no history of catheterization in past and also there was no history of taking gonadotrophin-releasing hormone analogs or uterine artery embolization. There was no significant past and family history.

On general examination, she was febrile $\left(100^{\circ} \mathrm{F}\right)$ with pulse 100/minute. She was normotensive and mild pallor was present. Cardiovascular and respiratory examination revealed no abnormality. On abdominal examination, a mass of 20 weeks pregnant uterine size was palpable. The bladder was catheterized with the Foley's catheter and $800 \mathrm{cc}$ of urine was drained. After catheterization, size of the mass reduced to 16 weeks size, and the lower border could not be reached. It was firm and tender with a smooth surface and restricted mobility. Per speculum examination revealed no abnormality. Per vaginal and perrectal examination was suggestive of large posterior wall fibroid (16 weeks), which was tender and immobile. Clinical diagnosis was large posterior wall fibroid with retention of urine.

Routine blood investigations and ultrasonography of the abdomen and the pelvis were done. Ultrasound showed normal kidneys and $10 \times 10 \times 10 \mathrm{~cm}$ size posterior wall fibroid with normal ovaries. Urine microscopy and culture showed no evidence of infection. Total count was $16,600 / \mu \mathrm{L}$ with $84 \%$ polymorphs. In view
1-3,5 Department of Obstetrics and Gynecology, NKP Salve Institute of Medical Sciences and Research Centre and Lata Mangeshkar Hospital, Nagpur, Maharashtra, India

${ }^{4}$ Department of Pathology, NKP Salve Institute of Medical Sciences and Research Centre and Lata Mangeshkar Hospital, Nagpur, Maharashtra, India

Corresponding Author: Nirwana Agrawal, Department of Obstetrics and Gynecology, NKP Salve Institute of Medical Sciences and Research Centre and Lata Mangeshkar Hospital, Nagpur, Maharashtra, India, Phone: +91 7972046357, e-mail: nirwanagrawal@gmail.com

How to cite this article: Somalwar SA, Agrawal N, Kawthalkar A, et al. Red Degeneration of Leiomyoma: An Unusual Presentation. J South Asian Feder Obst Gynae 2019;11(5):318-320.

Source of support: Nil

Conflict of interest: None

of fever and pain in the abdomen, she was started with intravenous injection ciprofloxacin 500 mg 12 hourly, intravenous injection metronidazole $500 \mathrm{mg} 8$ hourly, and injection diclofenac sodium $75 \mathrm{mg} 12$ hourly. She had persistent fever. Dilatation and curettage was done as she had history of menorrhagia. Histopathology showed secretory endometrium.

Decision was taken to proceed for semiemergency surgery as fever and pain was persistent. She underwent total abdominal hysterectomy as she had completed family. Intraoperatively large posterior wall fibroid was present, which was impacted in the pouch of Douglas. The uterus could not be delivered out of the abdomen. After bilateral ligation of round ligaments and ovarian ligaments, myomectomy was done and then hysterectomy was completed. Postoperatively, she was afebrile and was passing urine normally.

The histopathology report was suggestive of red degeneration of fibroid (Fig. 1).

\section{Case 2}

Mrs. ND, 32 years old, was admitted with history of a lump in the abdomen since 8 days, pain in the abdomen, backache, and nausea since 2 days. She also had history of fever 4 days back for which she was treated by a local doctor. Her obstetric history revealed 


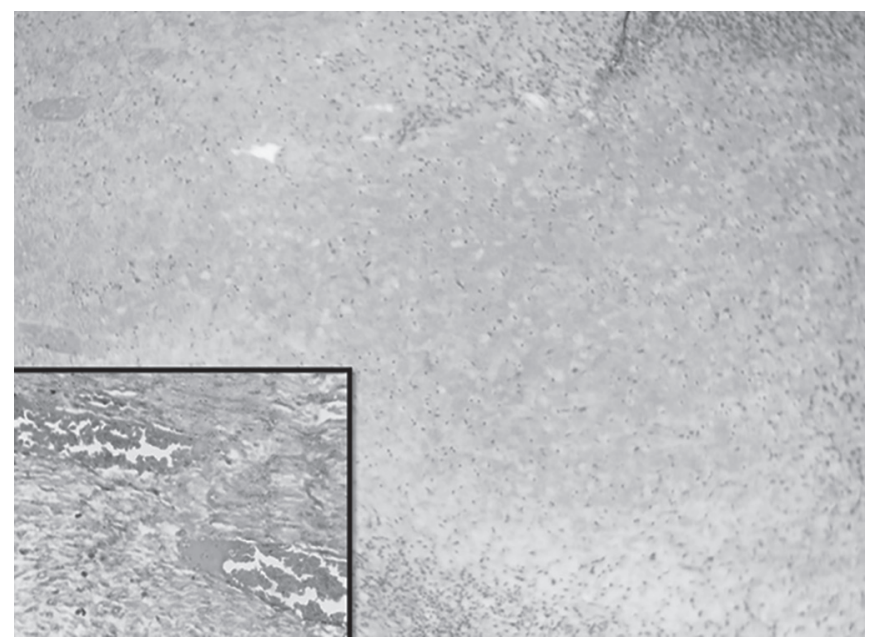

Fig. 1: $\mathrm{H}$ and $\mathrm{E}$ sections showing congested blood vessels (inset) and areas of extensive coagulative necrosis (case 1)

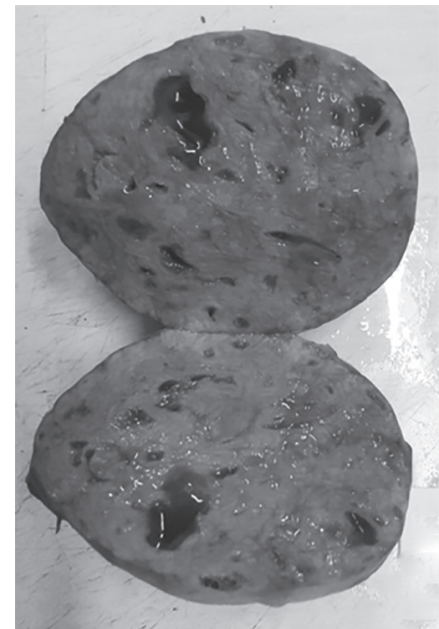

Fig. 3: Cut surface of fibroid showing red areas with hemorrhage (case 2)

that she was married since 12 years, nulligravida, and was not investigated for infertility. She had eumenorrheic cycles and the last menstrual period was 18 days back. Past and family history was not significant.

On general examination, she was afebrile with pulse 90/minute, normotensive, and had mild pallor. Cardiovascular and respiratory examination revealed no abnormality. On per abdominal examination, a lump of 24 weeks pregnant uterine size was palpable, which was firm with a smooth surface, mobile, tender, and the lower border could not be reached. Per speculum examination revealed no abnormality. Per vaginal examination showed a mass of 24 weeks pregnant uterine size, firm, tender, mobile, and cervical movements were transmitted to the mass. Perrectal examination confirmed same findings.

Learning from the first case, clinical diagnosis of the fibroid uterus with red degeneration was considered. She was started with intravenous fluids, injection diclofenac sodium 8 hourly, injection ciprofloxacin $500 \mathrm{mg} 12$ hourly, and injection metronidazole 500 mg 8 hourly. She responded to the treatment.

She was investigated. Her hemoglobin was $11 \mathrm{~g} \%$, TLC was $13,000 / \mathrm{mm}^{3}$ with polymorphs $88 \%$. Rest of investigations (blood

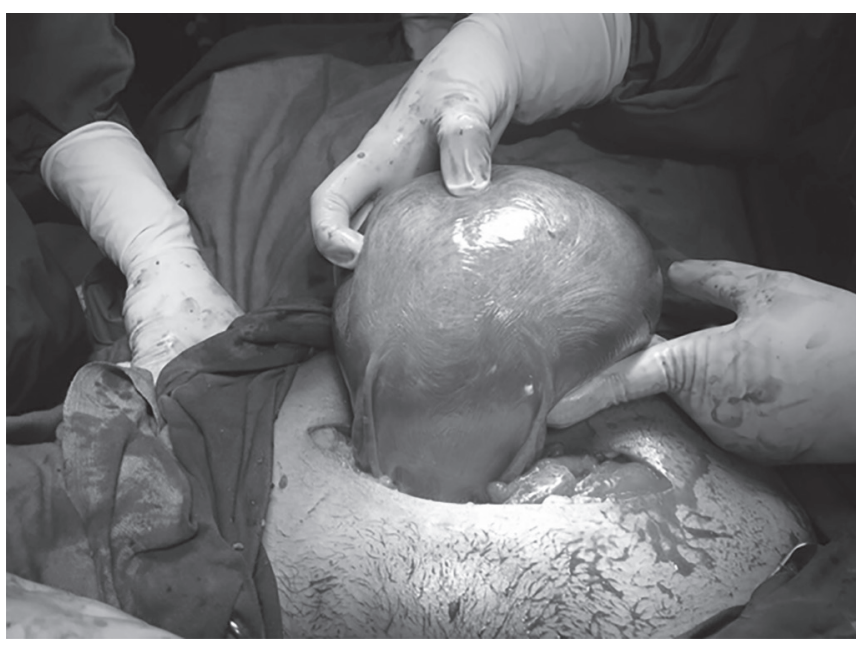

Fig. 2: Intraoperative photograph showing large fibroid arising from fundus of the uterus (case 2)

and urine) were normal. Ultrasonography showed large intramural fundal fibroid with normal ovaries and kidneys.

Considering her age and desire for further reproduction, decision of myomectomy was taken. Intraoperatively, there was large intramural fibroid arising from the fundus (Fig. 2). Myomectomy was done and the cut section (Fig. 3) showed red areas with hemorrhage and histopathology confirmed clinical diagnosis of red degeneration.

\section{Discussion}

Fibroid (leiomyoma) of the uterus is the most common benign condition found in women of the reproductive age group. It may be asymptomatic or can present with wide variety of symptoms like menstrual complaints, lump in the abdomen, pain in the abdomen, urinary complaints, pressure symptoms, and anemia.

Fibroid may undergo various types of degenerations such as hyaline, calcareous, fatty, myxomatous, and red degenerations.

Red degeneration of fibroid (carneous degeneration) is rare to occur and it has been mentioned in the literature that it occurs during pregnancy but rare in nonpregnant women.

Three main theories have been proposed to explain the severe pain associated with red degeneration. First, that rapid fibroid growth results in the tissue outgrowing its blood supply leading to tissue anoxia, necrosis, and infarction. ${ }^{2,3}$ Second, that the growing uterus results in a change in the architecture (kinking) of the blood supply to the fibroid leading to ischemia and necrosis even in the absence of fibroid growth. ${ }^{4}$ Third, that the pain results from the release of prostaglandins from cellular damage within the fibroid. This is supported by the observation that ibuprofen and other prostaglandin synthetase inhibitors effectively and rapidly control fibroid pain. ${ }^{2}$ The cause of fever in red degeneration is not mentioned in the literature but it can be because of release of prostaglandins.

It is mentioned in the literature that red degeneration of fibroid can occur after treatment of myoma with GnRh analogs or with uterine artery embolization. In these cases, there was no such history. Till now, only one case is reported in the literature of red degeneration of fibroid in nonpregnant woman. ${ }^{5}$ 
In nonpregnant women with the fibroid uterus having mild grade fever and pain in the abdomen, possibility of red degeneration should always be kept in mind.

\section{Acknowledgment}

We are grateful to the professor and head, Dr Sulabha Joshi, for permitting us to publish this case.

\section{References}

1. Sheila B. Benign diseases of uterus- fibroids and adenomyosis. Text Book of Gynaecology, 1st ed., ch. 16, 2010. p. 165.
2. Katz VL, Dotters DJ, Droegemueller W. Complications of uterine leiomyomas in pregnancy. Obstet Gynecol 1989;73(4): 593-596.

3. De Carolis S, Fatigante G, Ferrazzani S, et al. Uterine myomectomy in pregnant women. Fetal Diagn Ther 2001;16(2):116-119. DOI: 10.1159/000053893.

4. Parker WH. Etiology, symptomatology, and diagnosis of uterine myomas. Fertil Steril 2007;87(4):725-736. DOI: 10.1016/ j.fertnstert.2007.01.093.

5. Dasari P. A rare case of red degeneration of fibroid uterus. J Gynecol Surg 2010;26(1):63-66. DOI: 10.1089/gyn.2009.0018. 